\title{
Analysis of Eddy-Current Loss in a Double-Stator Cup-Rotor PM Machine
}

\author{
Shuangxia Niu ${ }^{1}$, K. T. Chau ${ }^{1}$, and J. Z. Jiang ${ }^{1,2}$ \\ ${ }^{1}$ Department of Electrical and Electronic Engineering, The University of Hong Kong, Hong Kong, China \\ ${ }^{2}$ School of Electromechanical Engineering and Automation, Shanghai University, Shanghai, China
}

In this paper, a new double-stator cup-rotor permanent-magnet brushless DC (PMBDC) machine is proposed and analyzed. Since the machine structure is so unique while its operating principle is so distinct, a numerical field approach, namely the circuit-field-torque grid-model time-stepping finite-element method (CFT-GM-TS-FEM), is newly developed to analyze the steady-state and dynamic characteristics of the machine. Particularly, the analysis of eddy-current loss in both the PMs and iron core of the machine is conducted. Experimental results are given for verification.

Index Terms-Eddy-current loss, finite-element method, permanent-magnet machine.

\section{INTRODUCTION}

D UE to its high power density and high efficiency, the permanent-magnet brushless DC (PMBDC) machine is very attractive for high-performance applications such as electric vehicles. Particularly, its double-stator topology has been identified as one of the most promising candidates to work as the integrated-starter-generator (ISG) for hybrid electric vehicles [1], [2]. However, because of its special structure which involves two stators, one rotor, and hence two air gaps, this machine generally suffers from difficulty in electromagnetic field analysis.

Over the years, the finite-element method (FEM) has been successfully developed for electromagnetic field analysis of those machines with special structures. Recently, the circuit-field-torque grid-model time-stepping finite-element method (CFT-TS-FEM) has been developed to analyze the dynamic characteristics of PMBDC motors [3]. Also, a grid model of PMs has been incorporated into the CFT-TS-FEM to analyze the eddy-current loss in PMs of a PMBDC motor [4]. It allows that the eddy current has return loops in the 2-D model. Its computational time is greatly reduced compared with the 3-D FEM.

The purpose of this paper is to propose and analyze a new double-stator PMBDC machine. In particular, the CFT-GM-TS-FEM will be newly developed to analyze the eddy-current loss of a 3-phase double-stator cup-rotor PMBDC machine. Both the single-layer winding and the double-layer winding of the stator will be discussed. Experimentation will be carried out to verify the analysis results.

\section{MACHINE STRUCTURE}

Fig. 1 shows the structure of the proposed machine in which there are two concentric stators and one cup-shaped rotor. Each stator has 24 slots wounded with 3-phase windings. Each phase winding conducts for $120^{\circ}$ and then nonconducting for $60^{\circ}$. Both the inside and outside surfaces of the rotor are separately mounted with 22 pieces of PMs.

The proposed machine has some distinct features. Firstly, the cup-shaped rotor can effectively shorten the magnetic circuit length, hence improving the torque density. Secondly, in order to minimize the cogging torque, fractional-slot winding

Digital Object Identifier 10.1109/TMAG.2008.2001346

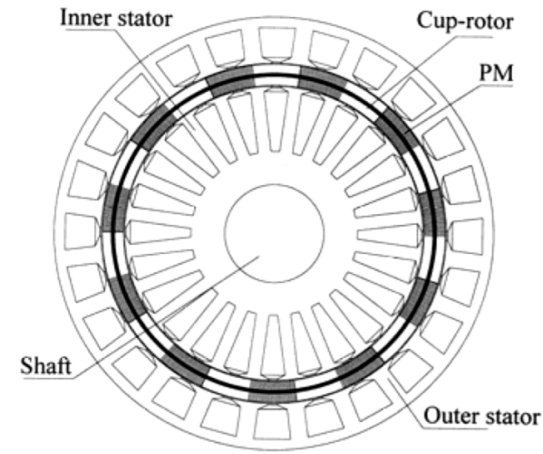

Fig. 1. Proposed double-stator PMBDC machine.

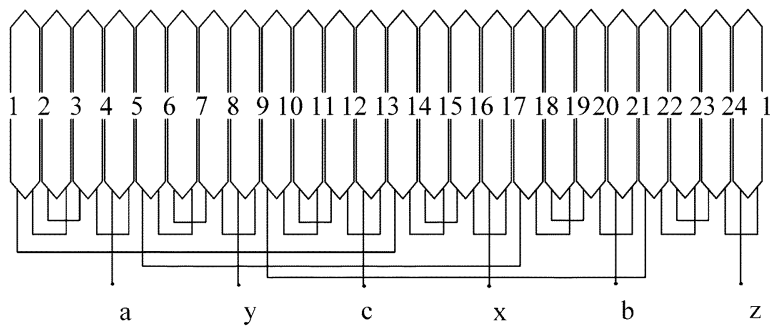

(a)

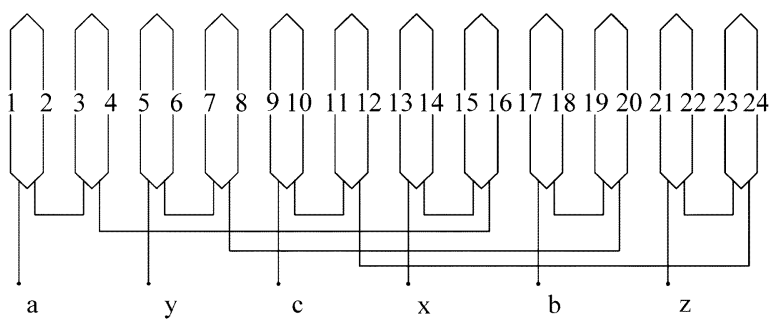

(b)

Fig. 2. Winding connections. (a) Double-layer winding. (b) Single-layer winding.

is adopted. The slot-pole relationship is given by $Q \pm 2=$ $2 p$, where $Q$ is the slot number and $2 p$ is the pole number. To make the flux paths of different phases symmetric and minimize the mutual inductance, the slot number of each stator also satisfies $Q=4 m k$, where $m$ is the phase number and $k=1,2,3 \ldots$ Thus, in this PMBDC machine, the slot-pitch is $11 / 12$ of the pole-pitch. Finally, to analyze the eddy-current loss with different winding distributions, two kinds of 3-phase winding connections, the single-layer winding and the doublelayer winding, are separately assessed as shown in Fig. 2. 


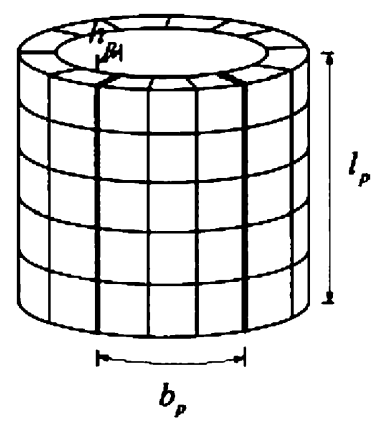

Fig. 3. Mesh loops of PMs and rotor iron core.

\section{ANALYSIS APPROACH}

Due to the unique structure and operating principle, the CFT-GM-TS-FEM is developed for analysis. The governing equation is given by

$\frac{\partial}{\partial x}\left(\frac{\partial A}{\partial x}\right)+\frac{\partial}{\partial y}\left(v \frac{\partial A}{\partial y}\right)=J+\sigma \frac{\partial A}{\partial t}-v \frac{\partial B_{r y}}{\partial x}+v \frac{\partial B_{r x}}{\partial y}$

where $A$ is the magnetic vector potential, $v$ is the reluctivity, $J$ is the current density, $\sigma$ is the electrical conductivity, and $B_{r x}, B_{r y}$ are the remanent flux density components of the PM.

In the stator conductor domain, the field, circuit and EMF equations are respectively given by

$$
\begin{aligned}
& \frac{\partial}{\partial x}\left(v \frac{\partial A}{\partial x}\right)+\frac{\partial}{\partial y}\left(v \frac{\partial A}{\partial y}\right)-\frac{i_{s}}{S}=0 \\
& V_{s}=R_{s} i_{s}+L_{e}\left(d i_{s} / d t\right)+e \\
& e=(l / S)\left(\iint_{\Omega^{+}}(\partial A / \partial t) d \Omega-\iint_{\Omega^{-}}(\partial A / \partial t) d \Omega\right)
\end{aligned}
$$

where $V_{s}$ is the supply voltage, $i_{s}$ is the stator current, $e$ is the induced back EMF, $R_{s}$ is the stator resistance of the phase winding, $L_{e}$ is the leakage inductance of the end winding, $l$ is the axial length of iron core, $\Omega^{+}$and $\Omega^{-}$are the cross-sectional areas of the phase conductors with opposite polarities, and $S$ is the average of $\Omega^{+}$and $\Omega^{-}$.

In the rotor domain, the key is to model the PMs and rotor iron core by a grid having $N$ bars along the circumferential direction and $M$ slices along the axial direction. The mesh loops of the PMs and rotor iron core are shown in Fig. 3, and the grid model is shown in Fig. 4. It can be seen that the eddy-current flow can form a complete loop which enhances the accuracy to calculate the eddy-current loss. The inter-bar resistance and the end resistance are respectively given by $R_{i}=b_{P} / N \sigma l_{M} h$ and $R_{k}=2 R_{i}$, where $l_{M}=l_{P} / M$ is the axial length of the $n$th bar of the $m$ th slice, $l_{P}$ is the axial length, $b_{P}$ is the width, $h$ is the thickness and $n=1,2, \ldots, N$. The depth of penetration of the PMs and rotor iron core is $\delta=\sqrt{2 / \omega \mu \sigma}$. If $\delta<h_{P}$, it yields $h=\delta$; otherwise, $h=h_{P}$, where $h_{P}$ is the thickness of the PMs and rotor iron core.

In the PMs and rotor iron core, the current density can be expressed as

$$
J=-\sigma(\partial A / \partial t)+u_{m n}\left(\sigma / l_{M}\right)
$$

where $u_{m n}$ is the voltage of the $n$th bar of the $m$ th slice. Thus, the eddy current of the $n$th bar of the $m$ th slice is given by

$$
i_{m n}^{\prime}=\sigma \iint_{\Omega_{m n}}\left(-\partial A / \partial t+u_{m n} / l_{M}\right) d \Omega .
$$

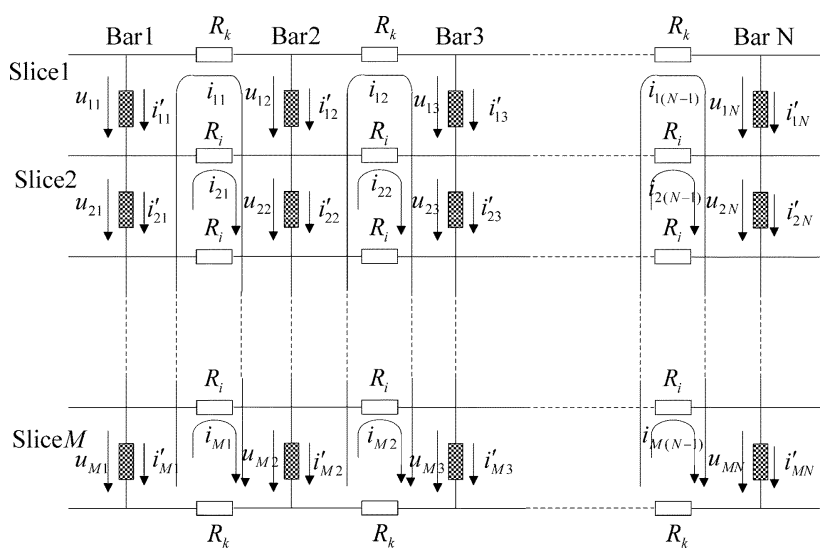

Fig. 4. Grid model of PMs and rotor iron core.

Hence, the branch equation can be formulated as

$$
\begin{aligned}
& \sigma \iint_{\Omega_{m n}}\left(-\frac{\partial A}{\partial t}+\frac{u_{m n}}{l_{M}}\right) d \Omega \\
& +\left[\begin{array}{lllll}
1 & 0 & 0 & & \mp 1 \\
-1 & 1 & 0 & & 0 \\
0 & -1 & 1 & \cdots & 0 \\
& & \vdots & \ddots & \\
0 & 0 & & -1 & 1
\end{array}\right]\left[\begin{array}{c}
i_{11} \\
i_{12} \\
i_{13} \\
\\
i_{1 N}
\end{array}\right] \\
& +\alpha\left[\begin{array}{lllll}
1 & 0 & 0 & & \mp 1 \\
-1 & 1 & 0 & & 0 \\
0 & -1 & 1 & \ldots & 0 \\
& & \vdots & \ddots & \\
0 & 0 & & -1 & 1
\end{array}\right]\left[\begin{array}{c}
i_{m 1} \\
i_{m 2} \\
i_{m 3} \\
i_{m N}
\end{array}\right]=0
\end{aligned}
$$

where $m=1,2, \ldots, M$ and $n=1,2, \ldots, N$. When $m=1$, it yields $\alpha=0$; otherwise, $\alpha=1$. If the bar 1 and bar $N$ are isolated electrically, the branch equation will be modified by $i_{m N}=0, m=1,2, \ldots, M$. If the bar $n$ and bar $n+1$ are isolated electrically, there will be additional constraints as given by $i_{m n}=0, m=1,2, \ldots, M$ [4]. Thus, the eddy-current loss in the PMs and rotor iron core can be calculated as

$$
\begin{aligned}
P_{\mathrm{PM}}= & \sum_{n=1}^{N} \sum_{m=1}^{M} \sigma l_{M} \iint_{\Omega_{m n}}\left(-\frac{\partial A}{\partial t}+\frac{u_{m n}}{l_{M}}\right)^{2} d \Omega \\
& +\sum_{n=1}^{N}\left[\sum_{m=3}^{M}\left(i_{m n}-i_{(m-1) n}\right)^{2} R_{i}\right. \\
& \left.+i_{2 n}^{2} R_{i}+i_{1 n}^{2} R_{k}+\left(i_{1 n}+i_{M n}\right)^{2} R_{k}\right] .
\end{aligned}
$$

In the air gap, the field equation is given by

$$
\frac{\partial}{\partial x}\left(v \frac{\partial A}{\partial x}\right)+\frac{\partial}{\partial y}\left(v \frac{\partial A}{\partial y}\right)=0 .
$$

By coupling the stator circuit and rotor equations together, the discretized system equation can be expressed as

$$
\begin{aligned}
{\left[C^{k}+\frac{D^{k}}{\Delta t}\right] } & {\left[A^{k} i_{s}^{k} u^{k} i_{r}^{k}\right]^{T} } \\
& =\left[\frac{D^{k}}{\Delta t}\right]\left[A^{k-1} i_{s}^{k-1} u^{k-1} i_{r}^{k-1}\right]^{T}+\left[P^{k}\right] .
\end{aligned}
$$




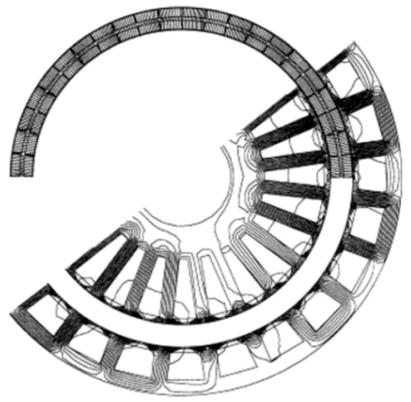

(a)

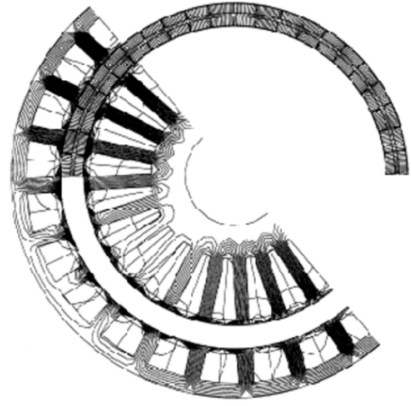

(b)
Fig. 5. Magnetic field distributions at full load. (a) Single-layer winding. (b) Double-layer winding.

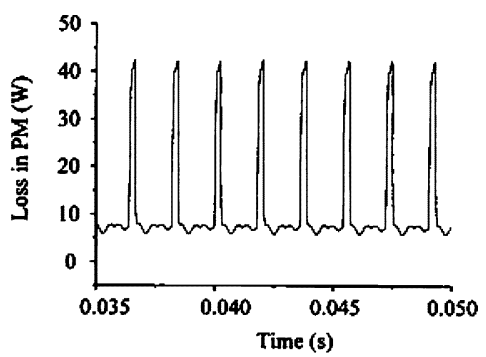

(a)

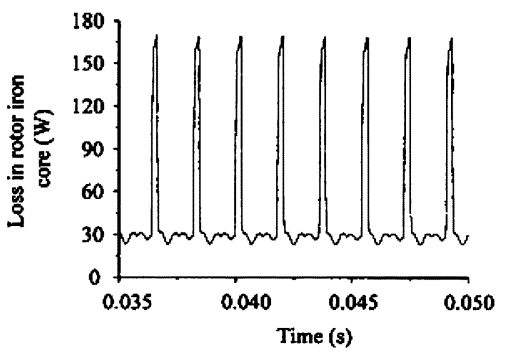

(b)

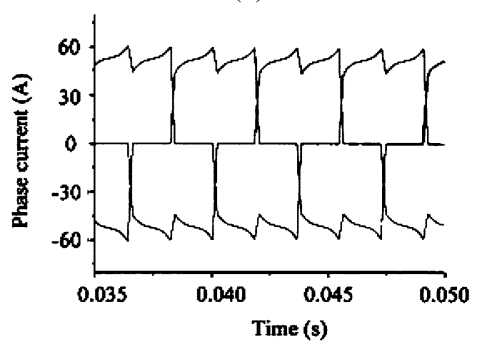

(c)

Fig. 6. Waveforms with single-layer winding. (a) Eddy-current loss in PMs. (b) Eddy-current loss in rotor iron core. (c) 3-phase currents.

The motion equation is given by

$$
J_{m}(d \omega / d t)=T_{e}-T_{L}
$$

where $J_{m}$ is the moment of inertia, $\omega$ is the rotor speed, $T_{e}$ is the electromagnetic torque, and $T_{L}$ is the load torque. Then, the Maxwell stress tensor method is used to calculate the electromagnetic torque at each step.

Based on the speed and position feedbacks from the FEM model, the stator current command can be deduced. Then, the current hysteresis controller is used to drive the PWM inverter, hence deducing the desired supply voltage for the FEM model.

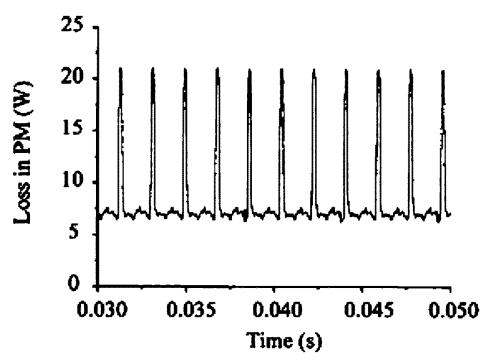

(a)

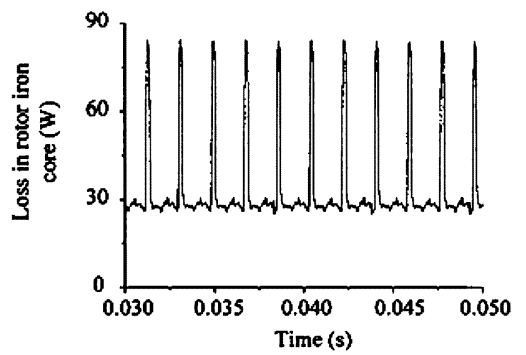

(b)

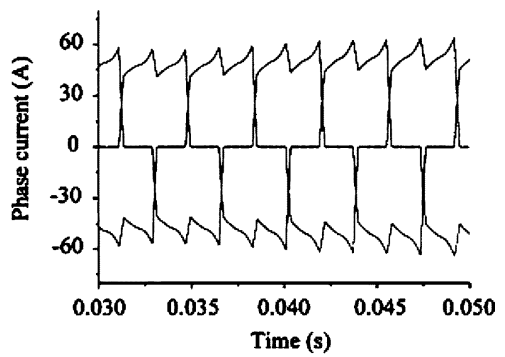

(c)

Fig. 7. Waveforms with double-layer winding. (a) Eddy-current loss in PMs. (b) Eddy-current loss in rotor iron core. (c) 3-phase currents.

\section{SimUlation AND EXPERIMENTAL RESUlTS}

Fig. 5 shows the magnetic flux density distributions at full load of the proposed PMBDC machine with the single-layer and double-layer windings. With the double-layer winding, the phase coils are distributed on 8 teeth; whereas with the singlelayer winding, the phase coils are distributed on 4 alternate teeth. Fig. 6 shows the eddy-current losses in the PMs and the rotor iron core as well as the 3-phase currents with the single-layer winding. The averages of the eddy-current loss in the PMs and rotor iron core are $15 \mathrm{~W}$ and $60 \mathrm{~W}$, respectively. Fig. 7 shows the eddy-current losses in the PMs and the rotor iron core as well as the 3-phase currents with the double-layer winding. The averages of the eddy-current loss in the PMs and rotor iron core are $9 \mathrm{~W}$ and $36 \mathrm{~W}$, respectively. It can be seen that the eddy-current loss in the PMs increases greatly within the commutation time. It is due to the fact that during the commutation of phase currents, there is a drastic change in the armature field and also the magnetic field in PMs, hence greatly increasing the eddy-current loss. Also, it can be found that the eddy-current loss with the double-layer winding is much less than that with the single-layer winding. The reason is that the single-layer winding has more concentrated winding distributions, which causes greater local armature reaction and hence higher eddy-current loss. This agrees with the argumentation in [5]. However, due to the fact that the single-layer winding has higher self-inductance and lower mutual inductance than the double-layer winding, it offers improved controllability for ISG 


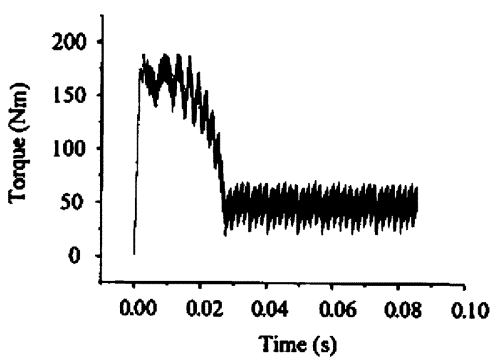

(a)

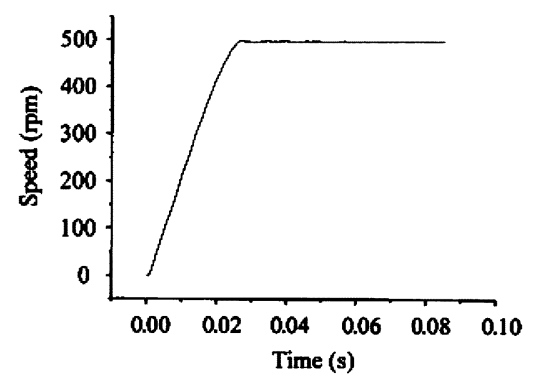

(b)

Fig. 8. Calculated start-up transient responses with single-layer winding. (a) Torque. (b) Speed.

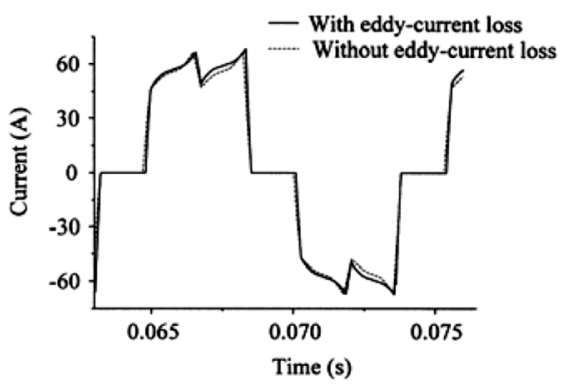

(a)

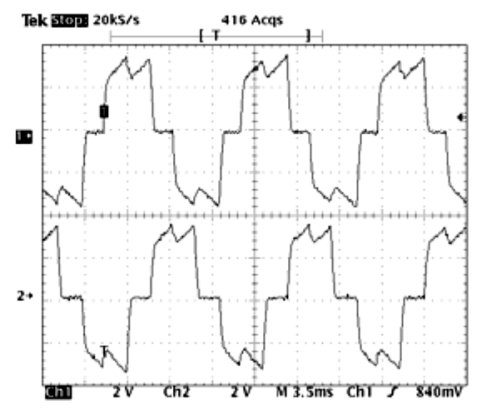

(b)

Fig. 9. Phase current waveforms with single-layer winding. (a) Calculated. (b) Measured (40 A/div).

TABLE I

COMPARISON OF CALCULATED AND MEASURED EFFICIENCIES

\begin{tabular}{llll}
\hline \hline & \multicolumn{2}{c}{ Calculated } & Measured \\
\hline Output power & $2500 \mathrm{~W}$ & $2500 \mathrm{~W}$ & $2500 \mathrm{~W}$ \\
Stator iron core loss & $160 \mathrm{~W}$ & $160 \mathrm{~W}$ & \\
Windage loss and stray loss & $30 \mathrm{~W}$ & $30 \mathrm{~W}$ & \\
Stator copper loss & $100 \mathrm{~W}$ & $100 \mathrm{~W}$ & $\mathrm{NA}$ \\
Eddy-current loss in PMs & $15 \mathrm{~W}$ & $0 \mathrm{~W}$ & \\
Eddy-current loss in rotor iron core & $60 \mathrm{~W}$ & $0 \mathrm{~W}$ & \\
Input power & $2865 \mathrm{~W}$ & $2790 \mathrm{~W}$ & $2900 \mathrm{~W}$ \\
Efficiency & $87.3 \%$ & $89.6 \%$ & $86.2 \%$ \\
\hline
\end{tabular}

application. Thus, the single-layer winding structure is used for experimentation of the proposed PMBDC machine.

The start-up transient responses of torque and speed of the machine with the single-layer winding are shown in Fig. 8. It can be seen that the command speed of $500 \mathrm{rpm}$ can be reached within $0.03 \mathrm{~s}$. The corresponding maximum starting torque is almost 4 times the rated torque. Fig. 9 shows the simulated phase current waveforms (with and without considering the eddy-current loss) and the measured one when the machine operates at the rated conditions. It can be observed that the difference between the calculated stator currents with and without considering the eddy-current loss is not so significant. It is due to the fact that the eddy-current loss is small compared with the output power. Nevertheless, the simulated waveform, that has considered the eddy-current loss, can closely match with the measured one. Table I shows the comparison between the calculated and measured efficiencies in this PMBDC machine with the single-layer winding. The first and second columns of Table I denote the calculated values with and without considering the eddy-current loss, respectively. It verifies that the calculated efficiency, that with the eddy-current loss, closely agrees with the measured one.

\section{CONCLUSION}

A new double-stator cup-rotor PMBDC machine has been proposed and analyzed by using the CFT-GM-TS-FEM. The key is to develop a grid model of the PMs and rotor iron core so that the eddy-current loss can be calculated, while both the steady-state and dynamic performances can be analyzed. The eddy-current losses with the single-layer and the double-layer windings are compared. Finally, the analysis of the machine with the single-layer winding is experimentally verified.

\section{ACKNOWLEDGMENT}

The authors would like to acknowledge Dr. Dong Zhang for his contribution to finite-element analysis. This work was supported and funded by a Grant (Project No. HKU7105/07E) from the Research Grants Council, Hong Kong Special Administrative Region, China.

\section{REFERENCES}

[1] K. T. Chau and C. C. Chan, "Emerging energy-efficient technologies for hybrid electric vehicles," Proc. IEEE, vol. 45, no. 4, pp. 821-835, Apr. 2007.

[2] K. T. Chau, Y. B. Li, J. Z. Jiang, and C. Liu, "Design and analysis of a stator-doubly-fed doubly-salient permanent-magnet machine for automotive engines," IEEE Trans. Magn., vol. 42, no. 10, pp. 3470-3472, Oct. 2006.

[3] Y. Wang, K. T. Chau, C. C. Chan, and J. Z. Jiang, "Transient analysis of a new outer-rotor permanent-magnet brushless DC drive using circuitfield-torque time-stepping finite element method," IEEE Trans. Magn., vol. 38, no. 2, pp. 1297-1300, Mar. 2002.

[4] W. N. Fu and Z. J. Liu, "Estimation of eddy-current loss in permanent magnets of electric motors using network-field coupled multislice timestepping finite-element method,' IEEE Trans. Magn., vol. 38, no. 2, pp. 1225-1228, Mar. 2002.

[5] D. Ishak, Z. Q. Zhu, and D. Howe, "Eddy-current loss in the rotor magnets of permanent-magnet brushless machines having a fractional number of slots per pole," IEEE Trans. Magn., vol. 41, no. 9, pp. 2462-2469, Sep. 2005.

Manuscript received February 29, 2008. Current version published December 17, 2008. Corresponding author: S. Niu (e-mail: sxniu@eee.hku.hk). 